\title{
Pathway analysis of transcriptomic data shows immunometabolic effects of vitamin D
}

\author{
Amadeo Muñoz Garcia1,2, Martina Kutmon1,3, Lars Eijssen1, Martin Hewison², Chris T Evelo1,3 and Susan L Coort1 \\ 'Department of Bioinformatics - BiGCaT, NUTRIM School of Nutrition and Metabolism in Translational Research, Maastricht University, \\ Maastricht, The Netherlands \\ Institute of Metabolism and Systems Research, The University of Birmingham, Birmingham, UK \\ ${ }_{3}^{3}$ Maastricht Centre for System Biology (MaCSBio), Maastricht University, Maastricht, The Netherlands \\ Correspondence should be addressed to S L Coort: susan.coort@maastrichtuniversity.nl
}

\begin{abstract}
Unbiased genomic screening analyses have highlighted novel immunomodulatory properties of the active form of vitamin $\mathrm{D}, 1,25$-dihydroxyvitamin $\mathrm{D}\left(1,25(\mathrm{OH})_{2} \mathrm{D}\right)$. However, clearer interpretation of the resulting gene expression data is limited by cell model specificity. The aim of the current study was to provide a broader perspective on common gene regulatory pathways associated with innate immune responses to $1,25(\mathrm{OH})_{2} \mathrm{D}$, through systematic re-interrogation of existing gene expression databases from multiple related monocyte models (the THP-1 monocytic cell line (THP-1), monocytederived dendritic cells (DCs) and monocytes). Vitamin D receptor (VDR) expression is common to multiple immune cell types, and thus, pathway analysis of gene expression using data from multiple related models provides an inclusive perspective on the immunomodulatory impact of vitamin D. A bioinformatic workflow incorporating pathway analysis using PathVisio and WikiPathways was utilized to compare each set of gene expression data based on pathway-level context. Using this strategy, pathways related to the TCA cycle, oxidative phosphorylation and ATP synthesis and metabolism were shown to be significantly regulated by $1,25(\mathrm{OH})_{2} \mathrm{D}$ in each of the repository models (Z-scores 3.52-8.22). Common regulation by $1,25(\mathrm{OH})_{2} \mathrm{D}$ was also observed for pathways associated with apoptosis and the regulation of apoptosis (Z-scores 2.49-3.81). In contrast to the primary culture DC and monocyte models, the THP-1 myelomonocytic cell line showed strong regulation of pathways associated with cell proliferation and DNA replication (Z-scores 6.1-12.6). In short, data presented here support a fundamental role for active $1,25(\mathrm{OH})_{2} \mathrm{D}$ as a pivotal regulator of immunometabolism.
\end{abstract}

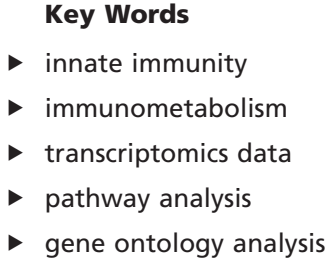

Journal of Molecular Endocrinology (2018) 60, 95-108

\section{Introduction}

In recent years, studies in vivo and in vitro have shown that vitamin $\mathrm{D}$ is able to influence biological responses that extend far beyond its classical effects on skeletal homeostasis. Prominent among these extra-skeletal effects is the interaction between vitamin D and the immune system, including regulation of both innate and adaptive immune responses (Adams \& Hewison 2008, Hewison 2011, Wei \& Christakos 2015). As a consequence of these observations, vitamin D deficiency has been linked to increased risk of bacterial and viral infection (Nnoaham \& Clarke 2008, Lake \& Adams 2011), as well as inflammatory and autoimmune disease (Cantorna 2012, 
Jeffery et al. 2016). The ability of supplementary or therapeutic vitamin D to prevent or improve these immune disorders is much less clear and is the subject of randomized placebo control trials currently underway. Crucially, improved understanding of the mechanisms that underpin the immunomodulatory actions of vitamin $\mathrm{D}$ has greatly helped to improve the design and outcome of clinical trials. In particular, unbiased analysis of gene responses to vitamin D supplementation has uncovered previously unrecognized immune targets for vitamin D (Liu et al. 2006, Chun et al. 2014) that are now key markers of vitamin $D$ function in supplementation trials.

The initial observation linking vitamin D and immune function was detection of the nuclear vitamin D receptor (VDR) in lymphocytic and myeloid cells (Bhalla et al. 1983, Mangelsdorf et al. 1984), indicating that these cells are able to respond to the active form of vitamin $\mathrm{D}, 1,25(\mathrm{OH})_{2} \mathrm{D}$, which binds with VDR. Further studies showed that cells from innate immune system such as monocytes/ macrophages (Kreutz et al. 1993) and dendritic cells (DC) (Hewison et al. 2003) are also able to synthesize $1,25(\mathrm{OH})_{2} \mathrm{D}$ from the inactive precursor 25-hydroxyvitamin D (25D), the main circulating form of vitamin D. As the principal effect of dietary vitamin D supplementation is to raise serum levels of 25D, the ability of monocytes and DCs to convert $25 \mathrm{D}$ to $1,25(\mathrm{OH})_{2} \mathrm{D}$ provides a localized, autocrine, pathway by which enhanced $25 \mathrm{D}$ can influence both innate and adaptive immunity (Liu et al. 2006, Jeffery et al. 2012). These observations placed monocytes and DCs at the center of the immunomodulatory activity of vitamin D. Synthesis of $1,25(\mathrm{OH})_{2} \mathrm{D}$ by these cells has the potential to influence endogenous innate immune cell function in the form of enhanced antibacterial activity (Liu et al. 2006, Hewison 2011) and/or modulated antigen presentation (Hewison et al. 2003, Jeffery et al. 2012). Furthermore, $1,25(\mathrm{OH})_{2} \mathrm{D}$ generated by monocytes and/or DCs may also impact adaptive immune function by exerting exogenous effects on T cells or B cells expressing VDR (Jeffery et al. 2012). Despite this, our understanding of the broader impact of vitamin D on cells from the innate immune system such as monocytes, macrophages and DCs remains far from clear.

Recent genome-wide expression studies using a monocyte-derived DC model highlighted the potential role of pathways associated with glucose metabolism, the TCA cycle and oxidative phosphorylation in mediating the effects of $1,25(\mathrm{OH})_{2} \mathrm{D}$ in promoting a tolerogenic DC phenotype (Ferreira et al. 2015). The aim of the current study was to provide a broader analysis of monocyte/DC responses to $1,25(\mathrm{OH})_{2} \mathrm{D}$ using existing gene expression repositories for multiple models of innate immune function. A meta-analysis of various datasets has been performed using an integrative workflow of opensource bioinformatics tools in order to give a biological context to the genes that are significantly modulated by $1,25(\mathrm{OH})_{2} \mathrm{D}$. Finally, a comparison between the immune cell types selected has been applied to highlight the common biological processes that are altered by vitamin D.

\section{Materials and methods}

\section{Workflow overview}

A workflow was developed that utilizes and integrates gene expression data from public repositories and places them in a biological context. Supplementary Figure 1 (see section on supplementary data given at the end of this article) illustrates step by step the different tools and methods used in the analysis workflow. The first procedure consisted of open and free modules in ArrayAnalysis to (i) perform a data quality check, (ii) normalize the raw transcriptomic data and (iii) perform a statistical analysis to obtain the parameters that show gene expression changes. The processed datasets were then applied to PathVisio, v. 3.2.4 software (van Iersel et al. 2008, Kutmon et al. 2015b) in order to perform statistical analyses that highlight the biological processes significantly altered as a consequence of gene expression changes and to visualize them in pathway diagrams from the WikiPathways pathway repository downloaded January 2017 (Kutmon et al. 2016). Comparison of the pathways shown to be significantly altered between the different cell types using PathVisio and WikiPathways was also represented by heat maps diagrams. In another approach, genes shown to be regulated by $1,25(\mathrm{OH})_{2} \mathrm{D}$ in all three cell models were used to identify enriched biological processes by gene ontology (GO) analysis and the results were visualized in biological networks using ClueGO, v 2.3.3 (Bindea et al. 2009), an app of Cytoscape 3.4.0 (Smoot et al. 2011) (Supplementary Fig. 1). This workflow is designed in a user-friendly fashion that does not require programming skills. In order to reproduce this workflow, it is recommended to use the latest versions of designated software. Furthermore, it is also important that gene annotation database and pathways repositories used in the analysis are regularly updated. 


\section{Transcriptomic datasets}

Publically available transcriptomic data sets for $1,25(\mathrm{OH})_{2} \mathrm{D}$-treated monocytes and dendritic cells (DC) were selected from ArrayExpress (https://www.ebi. ac.uk/arrayexpress/, (Kolesnikov et al. 2015)) and Gene Expression Omnibus (GEO, http://ncbi.nlm.nih.gov/ geo/, (Barrett \& Edgar 2006)). Selection criteria were based on gene expression studies performed in human cells including monocytic cell lines, monocytes and monocyte-derived DCs treated with $1,25(\mathrm{OH})_{2} \mathrm{D}$ : THP-1 cells (GSE52819 (Verway et al. 2013)), dendritic cells (GSE13762 (Széles et al. 2009)) and human monocytes (GSE56490 (Ferreira et al. 2015)). The selection of the three studies was based on experimental design and quality control analysis of the raw data. In all studies, data were derived from human immune cells treated with $1,25(\mathrm{OH})_{2} \mathrm{D}$ or from control (vehicle-treated) cells (Supplementary Table 1). In addition to the three cell models outlined previously, preliminary analyses were also carried out using other $1,25(\mathrm{OH})_{2} \mathrm{D}$-treated cell data repositories: THP-1 cells (GSE60102 (Nurminen et al. 2015)) and human monocytes (GSE46268 (Wheelwright et al. 2014)). In addition, the data for GSE13762 (Széles et al. 2009) included both immature and mature DC, and both these models were included in the preliminary analysis. Finally, as a negative control, the preliminary pathway analysis included a $1,25(\mathrm{OH})_{2}$ D-treated B cell dataset (GSE22523 (Lisse et al. 2011)). Because of missing raw data, incomplete gene annotation, incompatibility with ArrayAnalysis and non-monocyte origin, some data from the preliminary analysis were not included in the main analysis of this study, but relevant findings related to the data were addressed in the 'Results' section.

\section{Pre-processing raw data and statistical data analysis in ArrayAnalysis}

Unprocessed transcriptomics data were collected from the repositories and processed using the online workflow of ArrayAnalysis performed in January 2017 (https://www.arrayanalysis.org (Eijssen et al. 2013)) to obtain quality control reports, normalized data and perform statistical analysis. The workflow uses an $\mathrm{R}$ script as a core module with functions from several Bioconductor libraries. Quality control showed that there was no need to exclude any samples in the three selected transcriptomic datasets (data not shown). Depending on the microarray technology used, the normalization algorithm was selected. RMA method was used to normalize GSE52819 (Verway et al. 2013) and GSE56490 (Ferreira et al. 2015). GC-RMA method was applied to GSE13762 (Szeles et al. 2009). Statistical analysis of the normalized data to determine genes that are significantly altered (up/downregulated) was carried out with a second module from ArrayAnalysis including the moderated $t$-test from the R/Bioconductor package limma (Ritchie et al. 2009). The output is a table with the expression parameters for each gene showing fold-change (FC), in a $\log$ scale after $1,25(\mathrm{OH})_{2} \mathrm{D}$ treatment, and the significance of changes by the Benjamini-Hochberg adjusted $P$ value. Based on statistical gene expression parameters, the significantly up/downregulated genes were identified using the criteria: absolute $\log 2 \mathrm{FC} \geq 0.26$ and adjusted $P$ value $<0.05$. The average expression (AE) was used to filter out lowly expressed genes, and the cut-off was specific for each dataset based on the density plot of the intensities after normalization: THP-1 AE >4.25; immature $\mathrm{DC} \mathrm{AE}>3.86$ and monocytes $\mathrm{AE}>9.5$ (Table 1).

\section{Pathway statistics and analysis in PathVisio}

PathVisio v. 3.2 .4 (van Iersel et al. 2008, Kutmon et al. $2015 b$ ), an open-source pathway creation and analysis tool, was used to contextualize significantly altered genes, and altered biological processes were visualized using the biological pathway repository WikiPathways (Kutmon et al. 2016). Utilizing the BridgeDb identifier mapping feature released on 18 October 2016 (http:// www.bridgedb.org/) (van Iersel et al. 2010), PathVisio recognizes genes (probe) identifiers from the most used databases and microarray platforms such as NCBI and

Table 1 Regulation of gene expression by 1,25(OH) 2 D in THP-1, dendritic cells and monocyte models.

Dataset
Verway et al. (2013)
Széles et al. (2009)
Ferreira et al. (2015)

\begin{tabular}{l} 
Type of cell \\
\hline THP-1 \\
Immature DC \\
Monocytes \\
\hline
\end{tabular}

\begin{tabular}{c}
\hline Genes measured \\
\hline 21,664 \\
20,111 \\
21,664 \\
\hline
\end{tabular}

\begin{tabular}{c} 
Genes significantly altered \\
\hline 2652 \\
2093 \\
1248
\end{tabular}

\begin{tabular}{c}
\hline Genes upregulated \\
\hline 1194 \\
1130 \\
525
\end{tabular}

Genes downregulated 1458 963 723

Total number of genes measured for each gene expression repository and the number of genes with significantly altered expression. Genes with an absolute log fold-change $>0.26$ and adjusted $P$ value $<0.05$ were considered as regulated. Based on the expression parameter log fold-change genes are classified by upregulated (log fold-change $>0.26$ ) and downregulated (log fold-change <-0.26). 
Affymetrix. This identifier mapping database (Homo sapiens Derby Ensembl 85 gene database) enables linking of statistical values from analyzed data to the corresponding gene boxes in the pathway diagrams of WikiPathways. In the analysis, the curated human pathways collection (released April 2017, http://data. wikipathways.org/20170410/gpml/) of WikiPathways was used. For pathway analysis, a criterion is chosen to select genes that are significantly altered within each dataset based on the expression difference parameter of FC (on $\log 2$ scale) and the significance of that change is represented as the adjusted $P$ value $(<0.05)$. PathVisio performs an overrepresentation analysis taking into account all genes measured $(N)$, genes that satisfy the criterion $(R)$, genes measured in the experiment that are present in the pathway $(n)$ and genes in the pathway measured in the experiment that satisfy the criteria $(r)$ :

$$
\text { Zscore }=\frac{\left(r-n \frac{R}{N}\right)}{\sqrt{n\left(\frac{R}{N}\right)\left(1-\frac{R}{N}\right)\left(1-\frac{n-1}{N-1}\right)}}
$$

The $Z$-score is used to measure how significantly a subset of genes is altered in a certain pathway compared to the complete dataset. In our analysis, biological pathways that have a $Z$-score equal to or above 1.96 are considered significantly altered. The function heatmap. 2 from the $\mathrm{R}$ library gplots (v.3.0.1) was used to create a heatmap that compared and hierarchically clustered pathways for each of the datasets based on $Z$-scores.

\section{GO analysis with ClueGO in Cytoscape}

GO analysis of the common significantly altered genes (absolute $\log 2 \mathrm{FC} \geq 0.26$ and adjusted $P$ value $<0.05$ ) in the three types of immune cells was performed to identify and visualize which GO biological process terms were significantly overrepresented. Within the commonly used open-source network analysis tool Cytoscape, v. 3.4 (Smoot et al. 2011), the ClueGO app, $\mathrm{v}$ 2.3.3 performs GO analysis to group a set of genes in GO terms minimizing redundancy and display their relationship in a network. Connections between the GO nodes containing a common subset of genes were calculated with kappa statistics based on the correlated genes that are grouped.

\section{Results}

Differentially expressed genes in 1,25(OH $)_{2}$ D-treated THP1 cells, dendritic cells and monocytes

A preliminary pathway analysis of multiple THP1, monocyte and DC datasets revealed common regulation of several key cell pathways by $1,25(\mathrm{OH})_{2} \mathrm{D}$ in cells from the myeloid lineage: electron transport, oxidative phosphorylation, the TCA cycle, glycolysis and gluconeogenesis and apoptosis. By contrast, the non-myeloid $B$ cell gene expression dataset showed no similarity with the myeloid effects of $1,25(\mathrm{OH})_{2} \mathrm{D}$, underlining the lineage-specific effects of $1,25(\mathrm{OH})_{2} \mathrm{D}$ (Supplementary Fig. 2). From this initial pathway analysis, it was also interesting to note that $1,25(\mathrm{OH})_{2} \mathrm{D}$ regulation of pathways associated with the cell cycle and cell proliferation were only observed in the myeloid leukemic cell line THP-1 and not the other non-neoplastic primary cell models used in the study (Supplementary Fig. 2). Because of incomplete raw data or gene annotation, or incompatibility with ArrayAnalysis, further, more detailed, pathway analysis was restricted to raw datasets for GSE52819, GSE13762 and GSE56490.

\section{Pathway analysis reveals altered biological processes based on molecular changes in $1,25(\mathrm{OH})_{2}$ D-treated immune cells}

Pathway overrepresentation analysis performed on immune cell datasets GSE52819, GSE13762 and GSE56490 generated a list of biological processes regulated by $1,25(\mathrm{OH})_{2} \mathrm{D}$ in each of the three different innate immune cell models. For each cell type, the significantly altered pathways were selected, and their Z-scores plotted and clustered in a heatmap (Fig. 1) showing $Z$-score comparisons for major affected pathways between the three cell models. Data indicate that $1,25(\mathrm{OH})_{2} \mathrm{D}$-regulated pathways were either cell specific or common to all three models. Pathways related to DNA replication, the cell cycle and cancer (retinoblastoma) showed high $Z$-scores and were more strongly regulated by $1,25(\mathrm{OH})_{2} \mathrm{D}$ in THP-1 cells, consistent with the proliferative leukemic nature of this cell line. By contrast, primary cells (DCs and monocytes) showed stronger $1,25(\mathrm{OH})_{2} \mathrm{D}$ regulation of pathways associated with glycolysis/gluconeogenesis and the apoptosis-related network due to altered Notch3 in ovarian cancer pathway relative to THP-1 cells, albeit at lower Z-scores than observed for THP-1-specific pathways. Pathways associated with apoptosis and apoptosis 

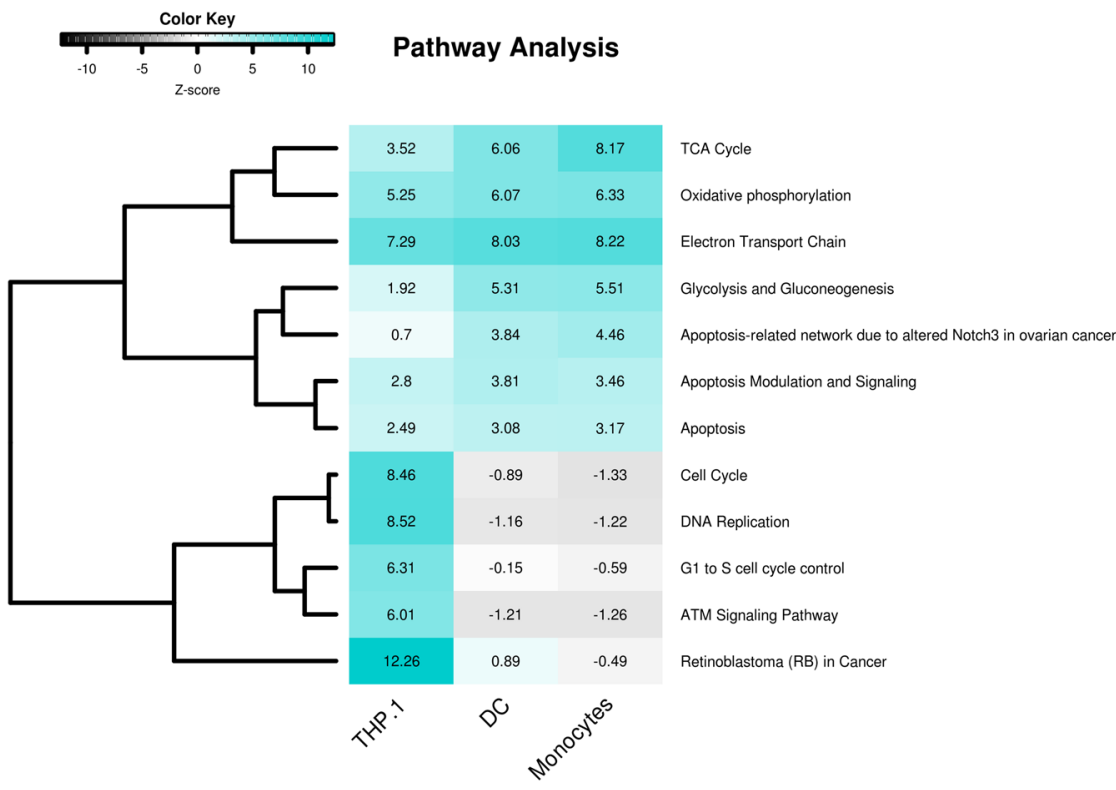
Figure 1
Common altered pathways in $1,25(\mathrm{OH})_{2}$ D-treated THP-1, DCs and monocytes. Heat map representing $Z$-scores for pathways significantly altered by $1,25(\mathrm{OH})_{2} \mathrm{D}$ after performing a pathway analysis on datasets for THP-1, DCs and monocytes treated with $1,25(\mathrm{OH})_{2}$ D. Z-Scores $>1.96$ indicate that more genes are significantly altered in this pathway compared to the complete dataset.

modulation and signaling also showed lower $Z$-scores, but were equally induced by $1,25(\mathrm{OH})_{2} \mathrm{D}$ in THP-1 cells, DCs and monocytes. The highest $Z$-score for $1,25(\mathrm{OH})_{2} \mathrm{D}$ regulated pathways common to all three cell models was for pathways related to the TCA cycle, oxidative phosphorylation and the electron transport chain.

\section{GO analysis shows metabolic, immunological and apoptotic processes altered by 1,25D in THP-1 cells, dendritic cells and monocytes}

ArrayAnalysis processing of GSE52819, GSE13762 and GSE56490 datasets was carried out to define the number of genes measured and number of genes significantly regulated by $1,25(\mathrm{OH})_{2} \mathrm{D}$ in each of the three cell models (Table 1). Further analysis of these data showed that a total of 230 genes were significantly regulated by $1,25(\mathrm{OH})_{2} \mathrm{D}$ in all three cell models (Fig. 2), and these genes were selected for subsequent GO analysis.

GO analysis using the list of 230 commonly altered genes was carried out using ClueGO in Cytoscape to display networks of overrepresented biological processes associated with this list. A total of 39 groups of GO terms resulted in the identification of three broad subnetworks common to each of the cell models (Fig. 3 and Supplementary Fig. 3A and B).

The first of these networks was associated with bioenergetic GO terms including the electron transport chain (GO:22904), oxidation-regulation process (GO:55114), oxidative phosphorylation (GO:6119), tricarboxylic acid cycle (GO:6099) and canonical glycolysis (GO:61621) (Fig. 3). A second sub-network was based on immunological GO terms such as responses to molecules of bacterial origin (GO:2237), cytokine production (GO:1816), inflammatory response (GO:6954) and myeloid cell differentiation (GO:30099) (Supplementary Fig. 3A).

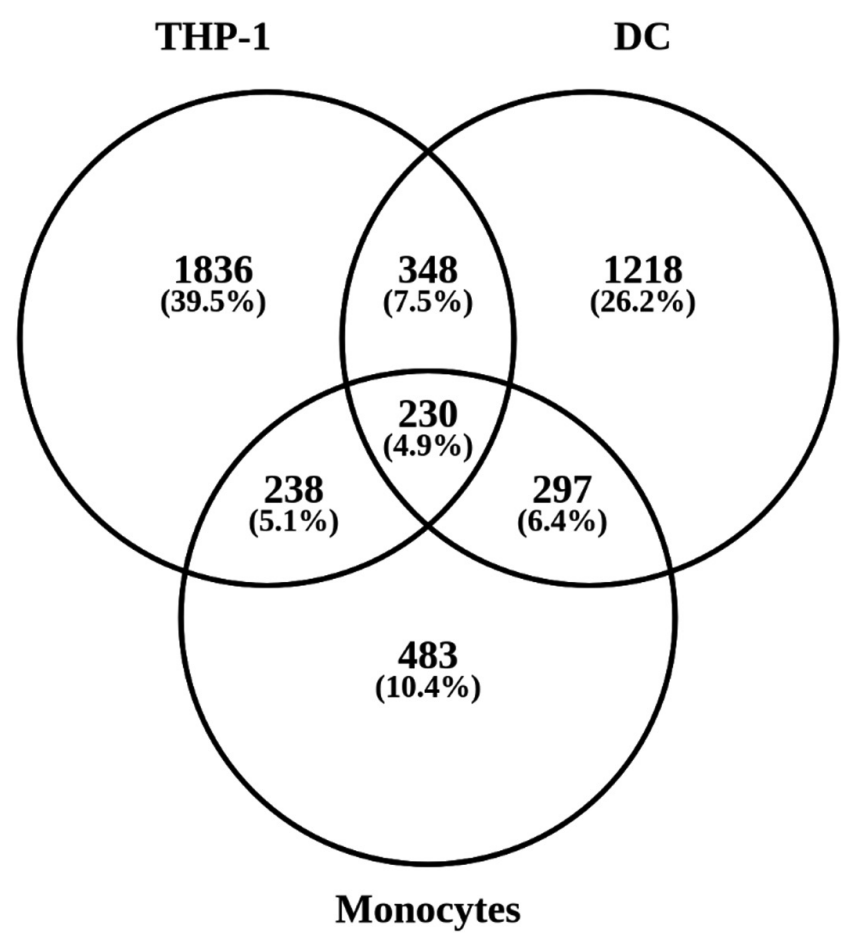

Figure 2

$1,25(\mathrm{OH})_{2} \mathrm{D}$-regulated genes in THP-1 cells, DCs and monocytes. Venn diagrams showing numbers of common and cell-specific genes regulated by $1,25(\mathrm{OH})_{2} \mathrm{D}$ in THP-1 cells, DCs and monocytes. Genes with an absolute log 2 fold-change $>0.26$ and adjusted $P$ value $<0.05$ were considered as regulated. 


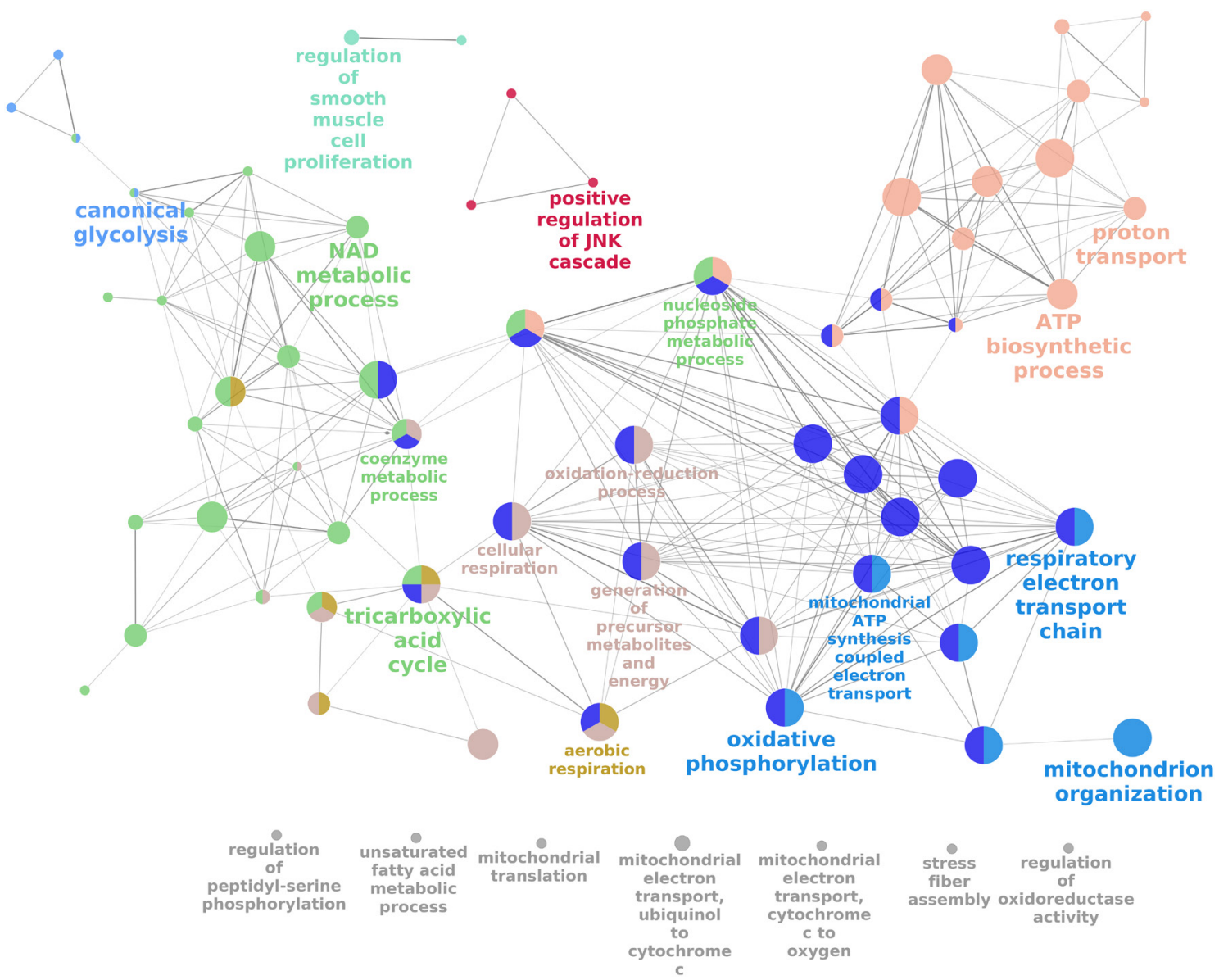

\section{Figure 3}

ClueGO gene ontology analysis of common 1,25(OH) 2 D-regulated bioenergetics genes in THP-1 cells, DCs and monocytes. Cytoscape analysis showing overrepresented bioenergetic pathways for $1,25(\mathrm{OH})_{2} \mathrm{D}$-treated THP-1 cells, DCs and monocytes. Colors represent the GO group, each node is a GO biological process and the edges shows the connectivity between each node based on the connection of the genes that contain. The size of the nodes depends on the amount of genes that are grouped. Nodes with no connections are colored in gray.

The final network identified that groups of apoptotic processes such as intrinsic apoptotic signaling (GO:97193) and negative regulation of apoptotic signaling (GO:2001234) (Supplementary Fig. 3B).

\section{Visualization of $1,25(\mathrm{OH})_{2} \mathrm{D}$-induced changes in gene expression in THP-1 cells, DCs and monocytes on altered metabolic pathways}

Pathways related to ATP metabolism showed high Z-scores $(>1.96)$, indicating strong regulation by $1,25(\mathrm{OH})_{2} \mathrm{D}$ (Fig. 2). To investigate the significant changes in gene expression in more depth, the effect of $1,25(\mathrm{OH})_{2} \mathrm{D}$ on gene expression was visualized on the altered metabolic pathways discovered with pathway analysis, i.e., electron transport chain, oxidative phoshorylation and TCA cycle and glycolysis.

\section{$1,25(\mathrm{OH})_{2} \mathrm{D}$ and the electron transport chain}

In the human electron transport chain pathway (Dahlquist et al. 2016a; http://wikipathways.org/index. php/Pathway:WP111), significantly upregulated or downregulated genes (adj. $P$ value $<0.05$ ) in the three immune cells treated with $1,25(\mathrm{OH})_{2} \mathrm{D}$ compared to untreated cells were collectively visualized. Overall, the electron transport chain was activated by $1,25(\mathrm{OH})_{2} \mathrm{D}$ in the three immune cells. Biological data in Fig. 4 shows in all three cell types a significant increase in expression by $1,25(\mathrm{OH})_{2} \mathrm{D}$ of genes associated with electron transport chain complexes I (NDUFA2, NDUFA3, NDUFA8, NDUFB9, NDUFA10, NDUFB5, NDUFAB1, NDUFS3, NDUFV1, NDUFS1), complex II (SDHB), complex III (UQRC1-2), complex IV (COX4l1, COX5A) and complex V (ATP5A1, ATP5B, ATP5C1, ATP5G1, ATP5L). Interestingly, the gene expression of the uncoupling protein 2 (UCP2) is 

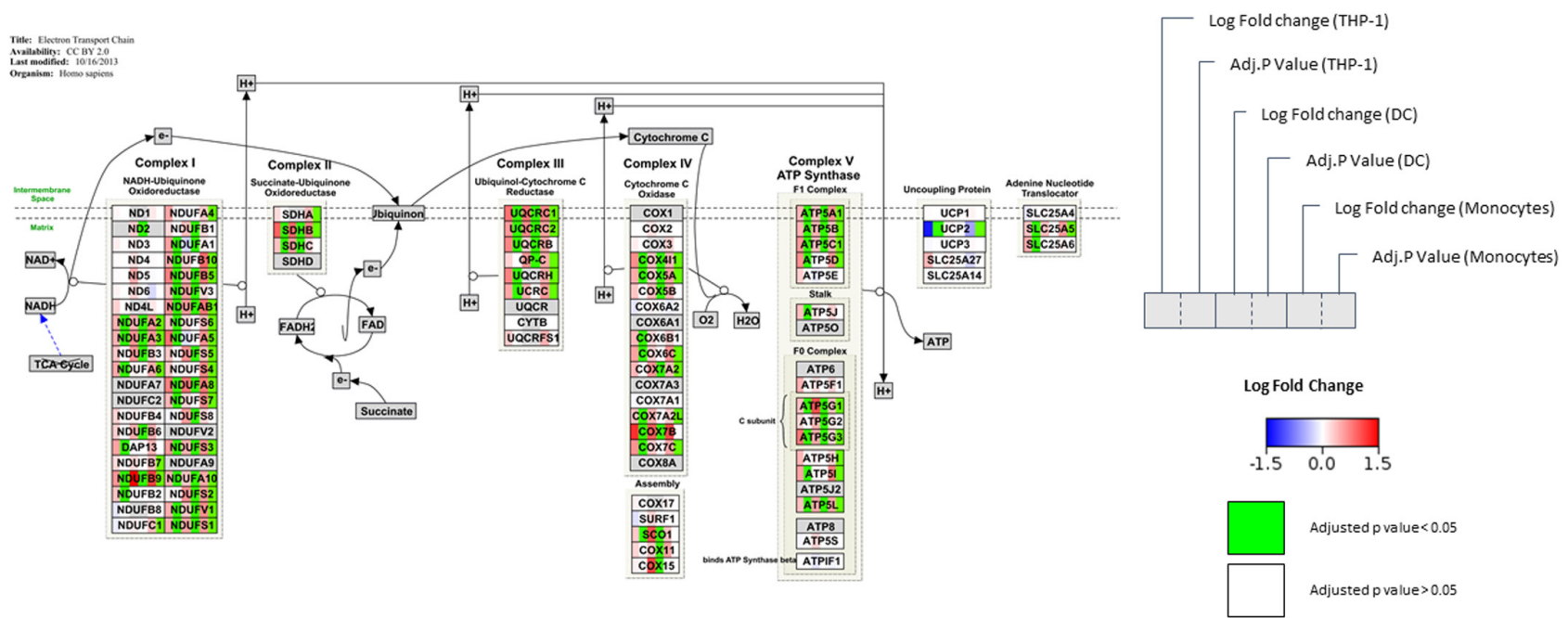

Figure 4

Effect of $1,25(\mathrm{OH})_{2} \mathrm{D}$ on genes associated with the electron transport chain. Visualization of changes in gene expression after $1,25(\mathrm{OH})_{2} \mathrm{D}$ treatment in THP-1 cells, DCs and monocytes. Log2 fold changes are shown as a gradient from blue (downregulated) to red (upregulated) over white (unchanged). Adjusted $P$-values $<0.05$ are shown in green.

significantly (adj. $P$ value $<0.05$ ) downregulated in THP-1 cells and monocytes by $1,25(\mathrm{OH})_{2} \mathrm{D}$, but unchanged in dendritic cells.

\section{$1,25(\mathrm{OH})_{2} \mathrm{D}$ and oxidative phosphorylation}

In the oxidative phosphorylation pathway (Waagmeester et al. 2017; http://wikipathways.org/index.php/ Pathway:WP623) all significantly changed genes were upregulated, demonstrating that this process is activated by $1,25(\mathrm{OH})_{2} \mathrm{D}$ in THP-1 cells, DCs and monocytes. Biological data in Fig. 5 show that specifically genes related to ATP synthase (ATPG3, ATP5G1, ATP5B, ATP5G1, ATP5A1, ATP5L) and nicotinamide nucleotide transhydrogenase (NDUFA3, NDUFS3, NDUFV1, NDUFA10, NDUFA8, NUDFB9 NDUFS1, NDUFB5, NDUFAB1, NDUFA2) are significantly (adj. $P$ value $<0.05$ ) upregulated by $1,25(\mathrm{OH})_{2} \mathrm{D}$ in each of the cell models.
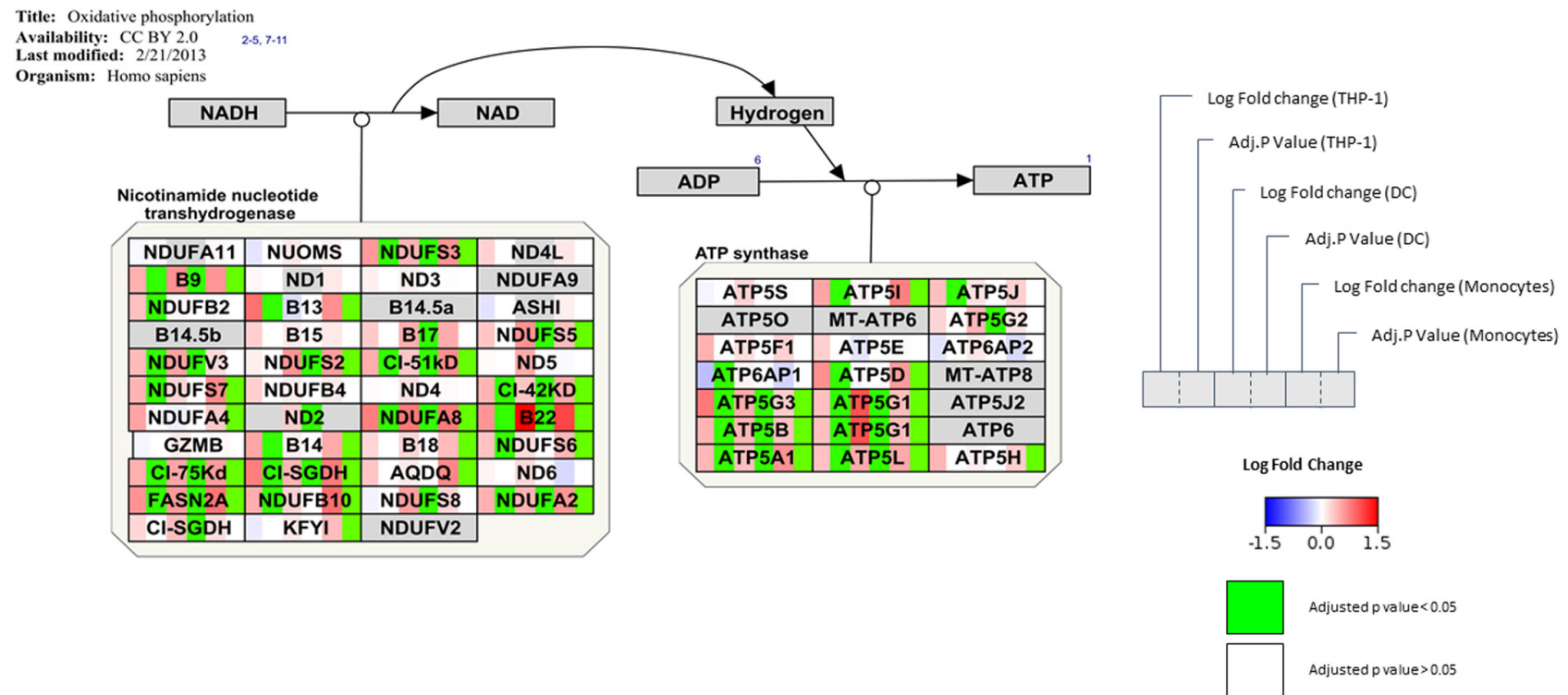

Figure 5

Effect of $1,25(\mathrm{OH})_{2} \mathrm{D}$ on genes associated with oxidative phosphorylation. Visualization of changes in gene expression after $1,25(\mathrm{OH})_{2} \mathrm{D}$ treatment in THP-1 cells, DCs and monocytes. Log2 fold changes are shown as a gradient from blue (downregulated) to red (upregulated) over white (unchanged). Adjusted $P$-values $<0.05$ are shown in green. 


\section{$1,25(\mathrm{OH})_{2} \mathrm{D}$ and the TCA cycle and glycolysis}

In the TCA cycle (Dahlquist et al. 2016b http:// wikipathways.org/index.php/Pathway:WP78), the process that produces energy by oxidation of acetyl$\mathrm{CoA}, 1,25(\mathrm{OH})_{2} \mathrm{D}$ upregulates genes involved in the conversion of acetyl-CoA in carbohydrate and chemical energy. $1,25(\mathrm{OH})_{2} \mathrm{D}$ increased the expression of $\mathrm{ACO} 2$, IDH3, IDH4B, DLD, SUCLG1, SDHB and MDH2 and only the expression of $I D H 2$, which functions in the opposite direction of the cycle, was significantly (adj. $P$ value $<0.05$ ) downregulated (Fig. 6). Glucose metabolism was also affected by $1,25(\mathrm{OH})_{2} \mathrm{D}$, with enzymes such as $H K 2$, $P F K M$ and FBP1 being significantly (adj. $P$ value $<0.05$ ) upregulated after treatment (Supplementary Fig. 4).

\section{$1,25(\mathrm{OH})_{2} \mathrm{D}$ and cell proliferation}

Analysis of both THP-1 cell datasets $(18,19)$ revealed that $1,25(\mathrm{OH})_{2} \mathrm{D}$ had a significant effect on genes associated with the cell cycle (Conklin et al. 2017 https://www. wikipathways.org/instance/WP179_r93002) (Fig. 7A). This included suppression of complexes involved in phase transitions and checkpoint signaling such as BUB1/BUB3, p34cdc2/cyclin B, Chk1/Chk2 and cell cyclin-dependent kinases (CDKs) such as CDK1, CDK2 and associated cyclins A1, A2, B1, B2 and E1, E2. THP-1 cells treated with $1,25(\mathrm{OH})_{2} \mathrm{D}$ also showed decreased expression of genes associated with DNA replication (Koren et al. 2017 https://www.wikipathways.org/instance/WP466_ r94886) (Fig. 7B). This included suppression of subunits of the maintenance protein complex (MCM), needed to initiate and elongate the replication fork in the DNA replication. $1,25(\mathrm{OH})_{2} \mathrm{D}$ also suppressed expression of genes that participate in progression of the cell cycle such as components of the assembly of the pre-replicative complex. This includes subunits of the component of the origin recognition complex (ORC): ORCL 1, 3 and 6 . Genes that participate in the assembly of pre-replicative DNA complexes were also downregulated by $1,25(\mathrm{OH})_{2} \mathrm{D}$. These include CDC6 and CDT1/GMNN complex. Finally, components of the DNA polymerase (POLa2, POLa, POLe2), primase (PRIM1, PRIM2) and subunits of the replication factor $\mathrm{C}$ (RFC1-5) were also downregulated by $1,25(\mathrm{OH})_{2} \mathrm{D}$ in THP-1 cells (Supplementary Fig. $5 \mathrm{~A}$ and B). In contrast to effects in leukemic THP-1 cells, pathways associated with cell proliferation and cell cycling were unaffected by $1,25(\mathrm{OH}) 2 \mathrm{D}$ in primary cultures of monocytes and dendritic cells (Supplementary Fig. 2).

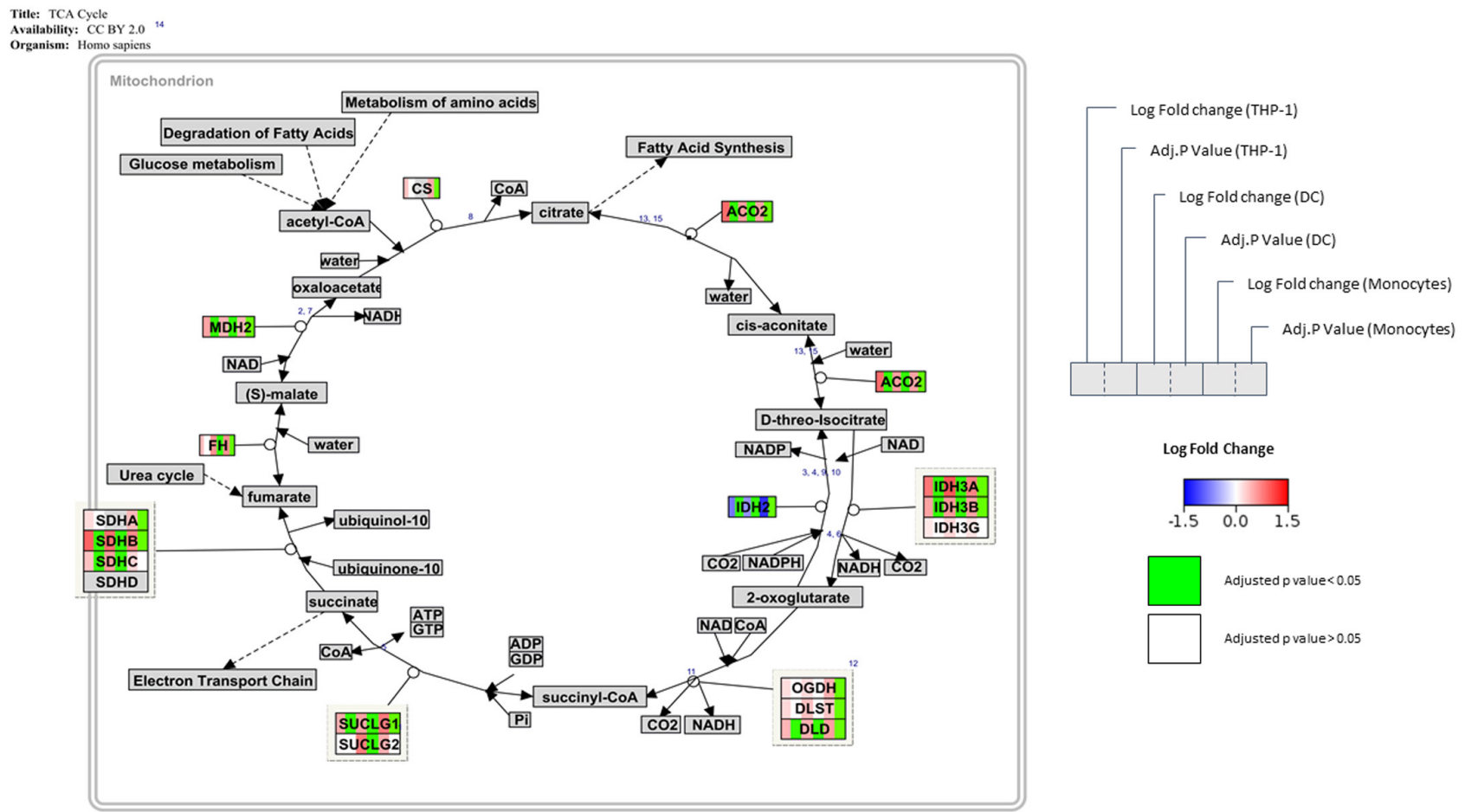

Figure 6

Effect of $1,25(\mathrm{OH})_{2} \mathrm{D}$ on genes associated with the TCA cycle. Visualization of changes in gene expression after $1,25(\mathrm{OH})_{2} \mathrm{D}$ treatment in THP-1 cells, DCs and monocytes. Log2 fold changes are shown as a gradient from blue (downregulated) to red (upregulated) over white (unchanged). Adjusted $P$-values $<0.05$ are shown in green. 
A
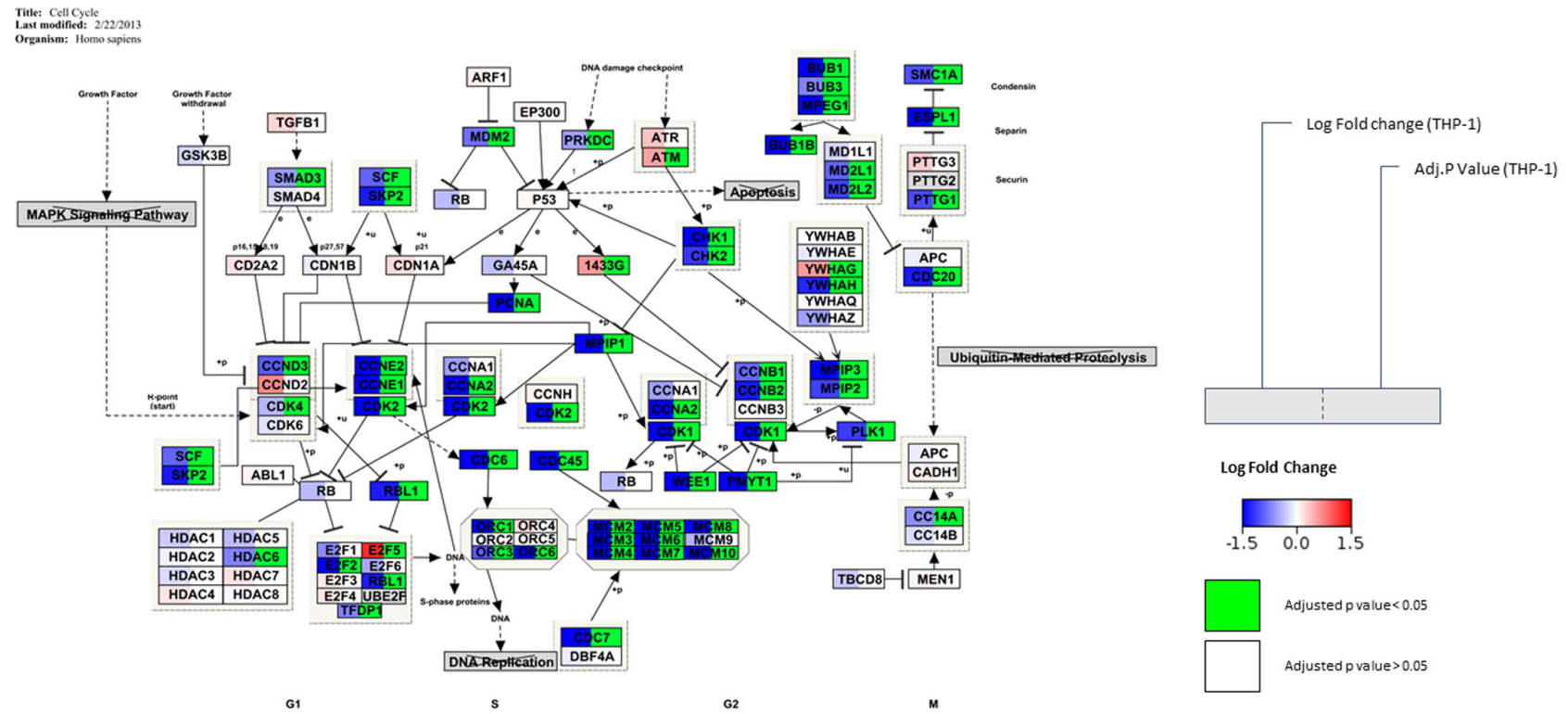

Log Fold Change

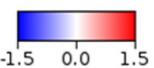

\section{B}

Titee: DNA Replication
Organism: Honno spiens
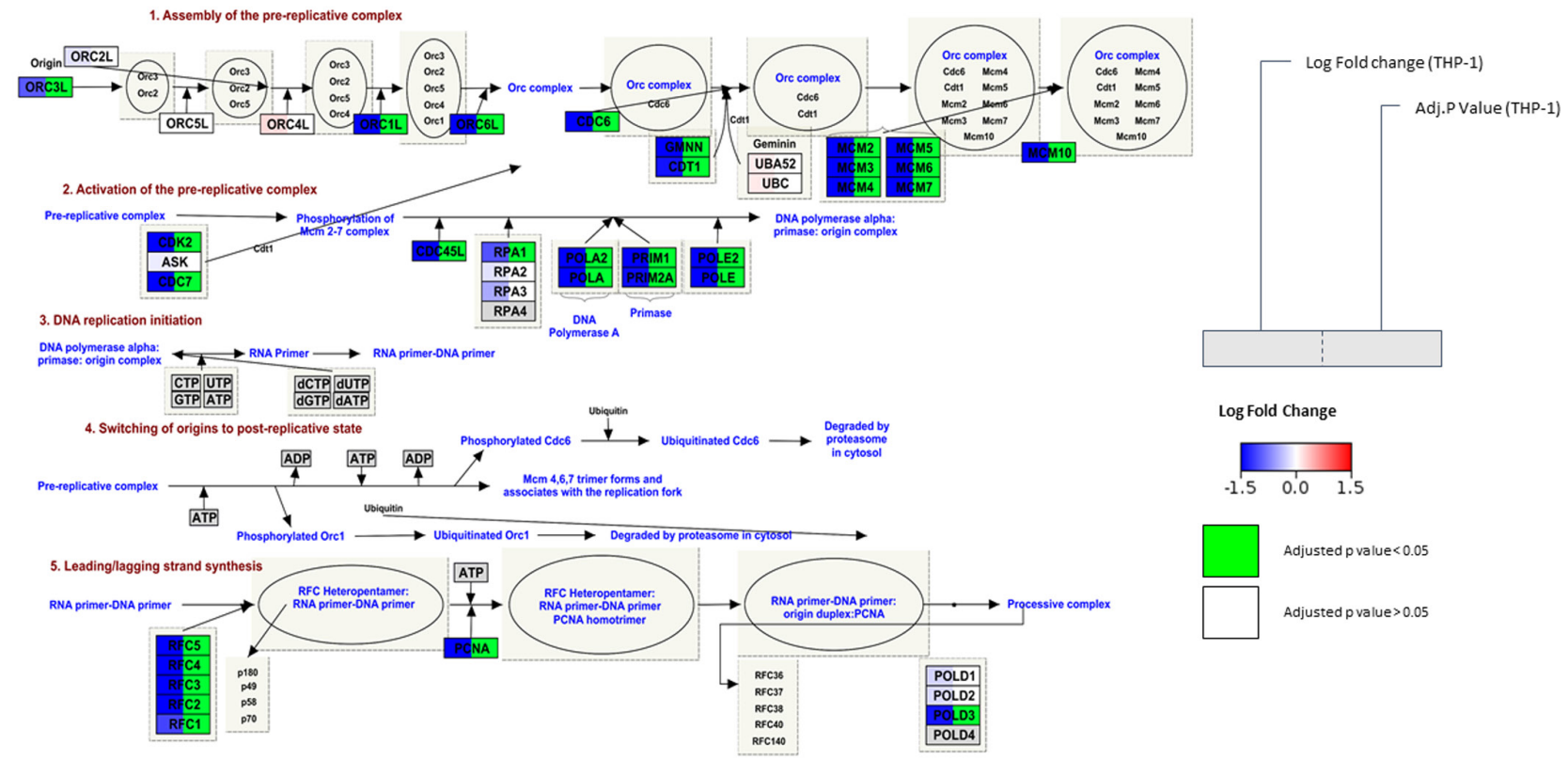

Log Fold Change

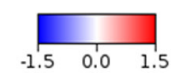

Adjusted p value $<0.05$

Adjusted p value $>0.05$

\section{Figure 7}

Effect of $1,25(\mathrm{OH})_{2} \mathrm{D}$ on the expression of genes associated with cell proliferation in THP-1 cells. WikiPathways representation of (A) cell cycle; (B) DNA replication pathways. Visualization of changes in gene expression after $1,25(\mathrm{OH})_{2} \mathrm{D}$ treatment in THP-1 cells. Log2 fold changes are shown as a gradient from blue (downregulated) to red (upregulated) over white (unchanged). Adjusted $P$-values $<0.05$ are shown in green.

\section{$1,25(\mathrm{OH})_{2} \mathrm{D}$ and apoptosis}

In the GO analysis, a network that relates apoptosis GO terms revealed three GO core groups: (1) negative regulation of apoptotic signaling; (2) intrinsic apoptotic signaling; (3) regulation of intrinsic apoptotic signaling pathway (Supplementary Fig. 3B). These groups include genes that were upregulated by $1,25(\mathrm{OH})_{2} \mathrm{D}$ in all three cells types such as: NDUFS3, TNFSF10, TRAP1, YBX3, NCK2, CEBPB, FXN, CYCS and NCK2. Conversely, CD74, DAPK1, ITGAV and FNIP2 were downregulated by $1,25(\mathrm{OH})_{2} \mathrm{D}$. 
Biological data in Supplementary Fig. 6A and B show significant effects of $1,25(\mathrm{OH})_{2} \mathrm{D}$ on pathways associated with apoptosis. The receptor TNFTSF10D that participates negatively in apoptosis is upregulated by $1,25(\mathrm{OH})_{2} \mathrm{D}$ in all three cell types, while the family of apoptotic caspases $(2,3,4,6$ and 7$)$ and the apoptotic peptidase-activating factor 1 (APAF1) are suppressed. Finally, it is interesting to note that JAK2 and MAP3K5 are downregulated by $1,25(\mathrm{OH})_{2} \mathrm{D}$ in THP-1 cells but upregulated in DCs and monocytes.

\section{Discussion}

Bioinformatics, or applying informatics to study biology, seeks to provide an unbiased and statistically robust insight into the molecular mechanisms that impact human health and disease. Large-scale projects such as the Human Genome Project (Roberts et al. 2001) and ENCODE (Consortium et al. 2007) have provided access to expansive repositories of data that have greatly helped to shed light on genomic function. However, utilization of these data repositories to answer specific biological questions remains limited. This is particularly true for studies of vitamin $\mathrm{D}$, despite detailed genome-wide analysis of VDR-chromatin interactions (Pike et al. 2017). In most cases, analysis of the genomic responses to $1,25(\mathrm{OH})_{2} \mathrm{D}-$ VDR complexes has been cell-specific, incorporating both classical calciotropic (Meyer et al. 2014) and extra-skeletal (Neme et al. 2016) effects of vitamin D. Recently, a more integrated approach to the bioinformatic interrogation of $1,25(\mathrm{OH})_{2} \mathrm{D}$-VDR datasets has been described, utilizing VDR-chromatin immunoprecipitation-sequencing (ChIPSeq) datasets with National Human Genome Research Institute (NHGRI) Genome-Wide Association Study (GWAS) Single-Nucleotide Polymorphism (SNP) datasets (Singh 2017). This strategy of combining publicly available datasets presents a distinct set of challenges, notably in establishing statistical rigor and appropriate analytical workflows, but nevertheless, provides a novel perspective on the role of vitamin D and the VDR in human health. Notably, integration of ChIP-seq-GWAS datasets emphasized an important role for VDR in regulating of target genes associated with immunomodulation (Singh 2017). The current study proposes an alternative bioinformatic approach to further interrogate the immunomodulatory function of $1,25(\mathrm{OH})_{2} \mathrm{D}-\mathrm{VDR}$. Utilizing pathway analysis workflows to assess multiple RNA expression datasets for monocyte-derived cell models allowed to the identification of common cellular pathways that are regulated by $1,25(\mathrm{OH})_{2} \mathrm{D}$, revealing an important new immunometabolic function for vitamin D. The analysis pipeline described here offers an alternative statistical approach to conventional software packages. The most notable advantage of the workflow presented here is that it is open source and user-friendly for the bioscience community and enables reproducible and straightforward methodology that can process data from different gene expression analysis platforms.

Transcriptomic analysis of gene regulatory responses has played a pivotal role in defining the innate immune functions of vitamin D (Chun et al. 2014). Notable studies have utilized specific monocyte (Liu et al. 2006) and dendritic cell (Ferreira et al. 2015) models to identify previously unrecognized molecular targets for active $1,25(\mathrm{OH})_{2} \mathrm{D}$, which have, in turn, revealed antibacterial (Adams et al. 2009, Bacchetta et al. 2014, Chun et al. 2015) and metabolic regulatory (Vanherwegen et al. 2017) functions for vitamin D in these cells. Collation of data from these different studies provides an alternative strategy for analysis of the immunomodulatory function of vitamin $\mathrm{D}$, by incorporating groups of regulated genes into cellular pathway analyses. Using this strategy, it was possible to identify common cellular processes that are regulated by $1,25(\mathrm{OH})_{2} \mathrm{D}$, as well as those that are more cell lineage specific. The major advantage of this workflow is that it contextualizes the experimental data at the biological process level using interactive pathways. Based on criteria, the pathway statistics approach of PathVisio defines the genes that are significantly altered in the dataset and highlights the pathways of the WikiPathways repository that are altered after treatment with $1,25(\mathrm{OH})_{2} \mathrm{D}$. In our pathway analysis, we used the manually curated and up-to-date human pathway collection of WikiPathways containing a broad spectrum of biological processes, including well-described metabolic processes as well as signaling and gene regulatory processes. Pathway analysis not only highlights the altered biological processes based on changes in gene expression, but it enables the investigation of the relationship between genes and different datasets in great detail. This makes pathway analysis a suitable approach for an integrative and in-depth analysis of large-scale transcriptomic data.

The most striking observation from the current analysis is that in all three cell models, $1,25(\mathrm{OH})_{2} \mathrm{D}$ is strongly associated with changes in cellular metabolism, oxidative phosphorylation and energy generation. Oxidative phosphorylation has been shown to play an important role in promoting a tolerogenic phenotype in immune cells (Vats et al. 2006, Michalek et al. 2011). Previous studies have reported effects of $1,25(\mathrm{OH})_{2} \mathrm{D}$ on 
mitochondrial functionality and physiology, and pathways related to glucose metabolism in monocyte-derived DCs (Ferreira et al. 2015). In a similar fashion, serum $25(\mathrm{OH})$ D status has been linked to markers of bioenergetic pathways in human peripheral blood mononuclear cells (Calton et al. 2016), and active $1,25(\mathrm{OH})_{2} \mathrm{D}$ has been shown to increase production of ATP and ROS, as well as altering mitochondrial functionality and morphology by increasing its membrane potential and total mass of mitochondria in differentiating monocytes (Ferreira et al. 2015). It was therefore notable in the current study that the most significantly altered pathways common to all three innate immune cell types were those associated with mitochondrial function: TCA cycle, electron transport chain and oxidative phosphorylation. Collectively, these observations underline an important role for $1,25(\mathrm{OH})_{2} \mathrm{D}$ as a positive regulator of mitochondrial metabolism and bioenergetic pathways in immune cells. Interestingly, this effect of $1,25(\mathrm{OH})_{2} \mathrm{D}$ appears to be consistent not only across the three myeloid cell models studied in detail in Fig. 1, but is also observed within different DC subtypes. In the current study, we chose an immature DC (iDC) model which focused purely on the effect of $1,25(\mathrm{OH})_{2} \mathrm{D}$, although this was for a longer time period (5 days) than the other models. Nevertheless, further analysis showed that the pathway effects of $1,25(\mathrm{OH})_{2} \mathrm{D}$ on iDC over 5 days were similar to those observed in immuneactivated mature DC (mDC) treated with 1,25(OH)2D for $12 \mathrm{~h}$ (Supplementary Fig. 2).

Pathways associated with glycolysis and gluconeogenesis, such as the TCA cycle, were also significantly regulated by $1,25(\mathrm{OH})_{2} \mathrm{D}$ in all three cell types studied. Catabolism of glucose leads to the formation of pyruvate, a biomolecule that is then metabolized in the TCA cycle. At present, relatively little is known about the impact of vitamin D on the TCA cycle, other than clinical studies showing association between vitamin $\mathrm{D}$ deficiency and dysregulation of glucose metabolism like diabetes (Seida et al. 2014). The present study demonstrates that several genes involved in the glucose metabolism are significantly regulated by vitamin D (Supplementary Fig. 4). Comparison of the THP-1, DC and monocyte datasets showed that genes for enzymes such as hexokinase, phosphofructokinase and fructose-bisphosphatase are commonly upregulated after $1,25(\mathrm{OH})_{2} \mathrm{D}$ treatment. In contrast to oxidative phosphorylation and electron transport, the glycolysis/ gluconeogenesis effects of $1,25(\mathrm{OH})_{2} \mathrm{D}$ were less consistent with some genes showing opposite patterns of regulation in different cell types. It is nevertheless clear that the regulation of glucose metabolism is a key facet of $1,25(\mathrm{OH})_{2} \mathrm{D}$ regulation of myeloid cells.

Besides common targets for vitamin D in innate immune cells, analysis of multiple repositories also highlighted pathways that were cell model specific. In THP-1 cells only, $1,25(\mathrm{OH})_{2} \mathrm{D}$ potently regulated genes involved in progression of cell cycle and DNA replication, consistent with the neoplastic origin of these cells. The pathways with high $Z$-score include retinoblastoma in cancer, G1 to S cell cycle control, DNA replication and cell cycle, are similar to those reported previously for prostate cancer cells treated with $1,25(\mathrm{OH})_{2} \mathrm{D}$ (Kutmon et al. 2015a). This suggests that, in addition to its common metabolic innate immune targets, $1,25(\mathrm{OH})_{2} \mathrm{D}$ also has common antiproliferative targets in neoplastic cell types, including suppression of key proteins that participate in progression of the cell cycle and regulation of DNA replication (Kriebitzsch et al. 2009). Interestingly, pathway analysis of $1,25(\mathrm{OH})_{2} \mathrm{D}$ in prostate cancer cells (Kutmon et al. 2015a) did not reveal any significant regulation of the metabolic pathways as identified for monocytes and DCs in the current study. Thus, in the same way that suppression of cell cycle/DNA replication genes appears to be a cancer cell-specific effect of $1,25(\mathrm{OH})_{2} \mathrm{D}$, genes associated with oxidative phosphorylation and energy metabolism appear to be innate immune cell specific. Previous studies using THP-1 cells have also included analysis of the temporal variations in response to treatment with $1,25(\mathrm{OH})_{2} \mathrm{D}$ (Seuter et al. 2016). The datasets in this particular study did not conform to requirements for the comparative pathway analysis used in our current study. However, we were able to carry out a preliminary pathway analysis of these data (Supplementary Fig. 7). Here, it was notable that metabolic and cell cycle effects of $1,25(\mathrm{OH})_{2} \mathrm{D}$ were only observed after $24 \mathrm{~h}$ of treatment, suggesting that pathway regulation by vitamin $\mathrm{D}$ is highly time dependent.

The third major group of pathways shown to be regulated by $1,25(\mathrm{OH})_{2} \mathrm{D}$ in THP-1, monocytes and DCs were those associated with programmed cell death (apoptosis). Previous studies have reported pro-apoptotic effects of $1,25(\mathrm{OH})_{2} \mathrm{D}$ in primary cultures of monocytes, with this effect being mediated via interference with CD40 responses (Almerighi et al. 2009). Conversely, in the HL-60 leukemic cell line, $1,25(\mathrm{OH})_{2} \mathrm{D}$ was reported to promote resistance to apoptosis (Mosieniak et al. 2006). Furthermore, studies from our group have shown that antisense knockdown of VDR in another leukemic cell line, U937, promoted cell apoptosis (Hewison et al. 1996). Data from the current study further support a role for $1,25(\mathrm{OH})_{2} \mathrm{D}$ in regulating apoptosis of innate immune 
cells: common genes in the three datasets compared are commonly upregulated (TNFTSF1OD) and downregulated (caspases family proteins and APAF1).

\section{Conclusions}

Understanding the entire set of results of high-throughput gene expression studies has often been challenging, caused by the complicated process of data analysis, and the limited biological interpretation that could be extracted from the large datasets generated through bench experiments. As a consequence, genome-wide analyses have tended to focus on changes in expression for specific genes (Liu et al. 2006, Chun et al. 2014) or small groups of genes associated with a specific pathway (Ferreira et al. 2015). The aim of the current study was to provide, for the first time, an unbiased analysis of the function of vitamin D in immune cells at a broader pathway level. Our resulting data demonstrate the added value of implementing a workflow with different bioinformatic tools that allows us to analyze gene expression data in a rapid, automated and reproducible fashion, to highlight pathways that are significantly altered by $1,25(\mathrm{OH})_{2} \mathrm{D}$. It is possible to visualize and further interrogate these biological diagrams to provide a detailed description of the molecular effects of $1,25(\mathrm{OH})_{2} \mathrm{D}$ in different types of immune cells. Finally, comparison of different datasets has allowed us to identify pathways, notably those associated with cell metabolism, that are common to multiple different types of innate immune cells. This approach provides new insights into the immunomodulatory actions of vitamin $\mathrm{D}$, but also has important implications for the many other physiological responses linked to vitamin $\mathrm{D}$ in recent studies.

\section{Supplementary data}

This is linked to the online version of the paper at https://doi.org/10.1530/ JME-17-0186.

\section{Declaration of interest}

The authors declare that there is no conflict of interest that could be perceived as prejudicing the impartiality of the research reported.

\section{Funding}

A M G is supported by a PhD Studentship from the Maastricht-Birmingham PhD Programme. M H is supported by a Royal Society Wolfson Merit Award (WM130118) and National Institutes of Health (AR063910). M K is supported by the Dutch Province of Limburg.

\section{References}

Adams JS \& Hewison M 2008 Unexpected actions of vitamin D: new perspectives on the regulation of innate and adaptive immunity. Nature Clinical Practice: Endocrinology and Metabolism 4 80-90. (https://doi.org/10.1038/ncpendmet0716)

Adams JS, Ren S, Liu PT, Chun RF, Lagishetty V, Gombart AF, Borregaard N, Modlin RL \& Hewison M 2009 Vitamin d-directed rheostatic regulation of monocyte antibacterial responses. Journal of Immunology 182 4289-4295. (https://doi.org/10.4049/ jimmunol.0803736)

Almerighi C, Sinistro A, Cavazza A, Ciaprini C, Rocchi G \& Bergamini A 2009 1alpha,25-Dihydroxyvitamin D3 inhibits CD40L-induced proinflammatory and immunomodulatory activity in human monocytes. Cytokine 45 190-197. (https://doi.org/10.1016/j. cyto.2008.12.009)

Bacchetta J, Chun RF, Gales B, Zaritsky JJ, Leroy S, Wesseling-Perry K, Boregaard N, Rastogi A, Salusky IB \& Hewison M 2014 Antibacterial responses by peritoneal macrophages are enhanced following vitamin D supplementation. PLOS ONE 9 e116530. (https://doi. org/10.1371/journal.pone.0116530)

Barrett T \& Edgar R 2006 Mining microarray data at NCBI's Gene Expression Omnibus (GEO)*. Methods in Molecular Biology 338 175-190. (https://doi.org/10.1385/1-59745-097-9:175)

Bhalla AK, Amento EP, Clemens TL, Holick MF \& Krane SM 1983 Specific high-affinity receptors for 1,25-dihydroxyvitamin D3 in human peripheral blood mononuclear cells: presence in monocytes and induction in T lymphocytes following activation. Journal of Clinical Endocrinology and Metabolism 57 1308-1310. (https://doi. org/10.1210/jcem-57-6-1308)

Bindea G, Mlecnik B, Hackl H, Charoentong P, Tosolini M, Kirilovsky A, Fridman WH, Pages F, Trajanoski Z \& Galon J 2009 ClueGO: a Cytoscape plug-in to decipher functionally grouped gene ontology and pathway annotation networks. Bioinformatics 25 1091-1093. (https://doi.org/10.1093/bioinformatics/btp101)

Calton EK, Keane KN, Soares MJ, Rowlands J \& Newsholme P 2016 Prevailing vitamin D status influences mitochondrial and glycolytic bioenergetics in peripheral blood mononuclear cells obtained from adults. Redox Biology 10 243-250. (https://doi.org/10.1016/j. redox.2016.10.007)

Campbell MJ 2017 Bioinformatic approaches to interrogating vitamin D receptor signaling. Molecular and Cellular Endocrinology 453 3-13. (https://doi.org/10.1016/j.mce.2017.03.011)

Cantorna MT 2012 Vitamin D, multiple sclerosis and inflammatory bowel disease. Archives of Biochemistry and Biophysics 523 103-106. (https://doi.org/10.1016/j.abb.2011.11.001)

Chun RF, Liu PT, Modlin RL, Adams JS \& Hewison M 2014 Impact of vitamin D on immune function: lessons learned from genome-wide analysis. Frontiers in Physiology 5 151. (https://doi.org/10.3389/ fphys.2014.00151)

Chun RF, Liu NQ, Lee T, Schall JI, Denburg MR, Rutstein RM, Adams JS, Zemel BS, Stallings VA \& Hewison M 2015 Vitamin D supplementation and antibacterial immune responses in adolescents and young adults with HIV/AIDS. Journal of Steroid Biochemistry and Molecular Biology 148 290-297. (https://doi.org/10.1016/j. jsbmb.2014.07.013)

Conklin B, Pico A, Campillo Sach I, Kutmon M, Coort S, Yahaya B, Chichester C, Josip, Hanspers K, van Iersel M, Salomonis N, Dmitriev S, Kelder T 2017 Cell cycle (Homo sapiens). (available at www.wikipathways.org/instance/WP179_r93002)

Consortium EP, Birney E, Stamatoyannopoulos JA, Dutta A, Guigo R, Gingeras TR, Margulies EH, Weng Z, Snyder M, Dermitzakis ET, et al. 2007 Identification and analysis of functional elements in 1\% of the human genome by the ENCODE pilot project. Nature 447 799-816. (https://doi.org/10.1038/nature05874) 
Dahlquist K, Pico A, Hanspers K, Willighagen E, Chichester C, Slenter D, Jagers F, Kutmon M 2016a Electron Transport Chain (Homo sapiens). (available at www.wikipathways.org/instance/WP111_r95118)

Dahlquist K, Stobbe M, Pico A, Hanspers K, van Iersel M, Kelder T, Digles D, Willighagen E, Nijveen H, Fidelman N, et al. 2016b TCA Cycle (Homo sapiens). (available at: www.wikipathways.org/instance/ WP78_r90661)

Eijssen LM, Jaillard M, Adriaens ME, Gaj S, de Groot PJ, Muller M \& Evelo CT 2013 User-friendly solutions for microarray quality control and pre-processing on ArrayAnalysis.org. Nucleic Acids Research 41 W71-W76. (https://doi.org/10.1093/nar/gkt293)

Ferreira GB, Vanherwegen AS, Eelen G, Gutierrez AC, Van Lommel L, Marchal K, Verlinden L, Verstuyf A, Nogueira T, Georgiadou M, et al. 2015 Vitamin D3 induces tolerance in human dendritic cells by activation of intracellular metabolic pathways. Cell Reports.

Hewison M 2011 Antibacterial effects of vitamin D. Nature Reviews Endocrinology 7 337-345. (https://doi.org/10.1038/nrendo.2010.226)

Hewison M, Dabrowski M, Vadher S, Faulkner L, Cockerill FJ, Brickell PM, O'Riordan JL \& Katz DR 1996 Antisense inhibition of vitamin D receptor expression induces apoptosis in monoblastoid U937 cells. Journal of Immunology 156 4391-4400.

Hewison M, Freeman L, Hughes SV, Evans KN, Bland R, Eliopoulos AG, Kilby MD, Moss PA \& Chakraverty R 2003 Differential regulation of vitamin $\mathrm{D}$ receptor and its ligand in human monocyte-derived dendritic cells. Journal of Immunology 170 5382-5390. (https://doi. org/10.4049/jimmunol.170.11.5382)

Hochreiter S, Clevert DA \& Obermayer K 2006 A new summarization method for Affymetrix probe level data. Bioinformatics 22 943-949. (https://doi.org/10.1093/bioinformatics/btl033)

Jeffery LE, Wood AM, Qureshi OS, Hou TZ, Gardner D, Briggs Z, Kaur S, Raza K \& Sansom DM 2012 Availability of 25-hydroxyvitamin D3 to APCs controls the balance between regulatory and inflammatory $\mathrm{T}$ cell responses. Journal of Immunology 189 5155-5164. (https://doi. org/10.4049/jimmunol.1200786)

Jeffery LE, Raza K \& Hewison M 2016 Vitamin D in rheumatoid arthritis-towards clinical application. Nature Reviews Rheumatology 12 201-210. (https://doi.org/10.1038/nrrheum.2015.140)

Kolesnikov N, Hastings E, Keays M, Melnichuk O, Tang YA, Williams E, Dylag M, Kurbatova N, Brandizi M, Burdett T, et al. 2015 ArrayExpress update - simplifying data submissions. Nucleic Acids Research 43 D1113-D1116. (https://doi.org/10.1093/nar/gku1057)

Koren D, Kutmon M, Kelder T, Pico A, Hanspers K, Dahlquist K, Roudbari Z 2017 DNA Replication (Homos sapiens). (available at https://www.wikipathways.org/instance/WP466_r94886)

Kreutz M, Andreesen R, Krause SW, Szabo A, Ritz E \& Reichel H 1993 1,25-Dihydroxyvitamin D3 production and vitamin D3 receptor expression are developmentally regulated during differentiation of human monocytes into macrophages. Blood 82 1300-1307.

Kriebitzsch C, Verlinden L, Eelen G, Tan BK, Van Camp M, Bouillon R \& Verstuyf A 2009 The impact of 1,25(OH)2D3 and its structural analogs on gene expression in cancer cells - a microarray approach. Anticancer Research 29 3471-3483.

Kutmon M, Coort SL, de Nooijer K, Lemmens C \& Evelo CT 2015a Integrative network-based analysis of mRNA and microRNA expression in 1,25-dihydroxyvitamin D3-treated cancer cells. Genes and Nutrition 10 484. (https://doi.org/10.1007/s12263-015-0484-0)

Kutmon M, van Iersel MP, Bohler A, Kelder T, Nunes N, Pico AR \& Evelo CT 2015b PathVisio 3: an extendable pathway analysis toolbox. PLoS Computational Biology 11 e1004085. (https://doi. org/10.1371/journal.pcbi.1004085)

Kutmon M, Riutta A, Nunes N, Hanspers K, Willighagen EL, Bohler A, Melius J, Waagmeester A, Sinha SR, Miller R, et al. 2016 WikiPathways: capturing the full diversity of pathway knowledge. Nucleic Acids Research 44 D488-D494. (https://doi.org/10.1093/nar/gkv1024)

Lake JE \& Adams JS 2011 Vitamin D in HIV-infected patients. Current HIV/AIDS Reports 8 133-141. (https://doi.org/10.1007/s11904-011008-8)
Lin SM, Du P, Huber W \& Kibbe WA 2008 Model-based variancestabilizing transformation for Illumina microarray data. Nucleic Acids Research 36 e11. (https://doi.org/10.1093/nar/gkm1075)

Lisse TS, Liu T, Irmler M, Beckers J, Chen H, Adams JS \& Hewison M 2011 Gene targeting by the vitamin D response element binding protein reveals a role for vitamin D in osteoblast mTOR signaling. FASEB Journal 25 937-947. (https://doi.org/10.1096/ fj.10-172577)

Liu PT, Stenger S, Li H, Wenzel L, Tan BH, Krutzik SR, Ochoa MT, Schauber J, Wu K, Meinken C, et al. 2006 Toll-like receptor triggering of a vitamin D-mediated human antimicrobial response. Science $\mathbf{3 1 1}$ 1770-1773. (https://doi.org/10.1126/science.1123933)

Mangelsdorf DJ, Koeffler HP, Donaldson CA, Pike JW \& Haussler MR 1984 1,25-Dihydroxyvitamin D3-induced differentiation in a human promyelocytic leukemia cell line (HL-60): receptor-mediated maturation to macrophage-like cells. Journal of Cell Biology 98 391-398. (https://doi.org/10.1083/jcb.98.2.391)

Meyer MB, Benkusky NA, Lee CH \& Pike JW 2014 Genomic determinants of gene regulation by 1,25-dihydroxyvitamin D3 during osteoblast-lineage cell differentiation. Journal of Biological Chemistry 289 19539-19554. (https://doi.org/10.1074/jbc. M114.578104)

Michalek RD, Gerriets VA, Jacobs SR, Macintyre AN, MacIver NJ, Mason EF, Sullivan SA, Nichols AG \& Rathmell JC 2011 Cutting edge: distinct glycolytic and lipid oxidative metabolic programs are essential for effector and regulatory CD4+ T cell subsets. Journal of Immunology 186 3299-3303. (https://doi.org/10.4049/ jimmunol.1003613)

Millenaar FF, Okyere J, May ST, van Zanten M, Voesenek LA \& Peeters AJ 2006 How to decide? Different methods of calculating gene expression from short oligonucleotide array data will give different results. BMC Bioinformatics 7 137. (https://doi.org/10.1186/14712105-7-137)

Mosieniak G, Sliwinska M, Piwocka K \& Sikora E 2006 Curcumin abolishes apoptosis resistance of calcitriol-differentiated HL-60 cells FEBS Letters 580 4653-4660. (https://doi.org/10.1016/j. febslet.2006.07.038)

Neme A, Nurminen V, Seuter S \& Carlberg C 2016 The vitamin D-dependent transcriptome of human monocytes. Journal of Steroid Biochemistry and Molecular Biology 164 180-187. (https://doi. org/10.1016/j.jsbmb.2015.10.018)

Nnoaham KE \& Clarke A 2008 Low serum vitamin D levels and tuberculosis: a systematic review and meta-analysis. International Journal of Epidemiology 37 113-119. (https://doi.org/10.1093/ije/ dym247)

Nurminen V, Neme A, Ryynanen J, Heikkinen S, Seuter S \& Carlberg C 2015 The transcriptional regulator BCL6 participates in the secondary gene regulatory response to vitamin D. Biochimica et Biophysica Acta 1849 300-308. (https://doi.org/10.1016/j. bbagrm.2014.12.001)

Pike JW, Meyer MB, Lee SM, Onal M \& Benkusky NA 2017 The vitamin $\mathrm{D}$ receptor: contemporary genomic approaches reveal new basic and translational insights. Journal of Clinical Investigation 127 1146-1154. (https://doi.org/10.1172/JCI88887)

Ritchie ME, Carvalho BS, Hetrick KN, Tavare S \& Irizarry RA 2009 R/ Bioconductor software for Illumina's Infinium whole-genome genotyping BeadChips. Bioinformatics 25 2621-2623. (https://doi. org/10.1093/bioinformatics/btp470)

Roberts L, Davenport RJ, Pennisi E \& Marshall E 2001 A history of the human genome project. Science 291 1195. (https://doi.org/10.1126/ science.291.5507.1195)

Seida JC, Mitri J, Colmers IN, Majumdar SR, Davidson MB, Edwards AL, Hanley DA, Pittas AG, Tjosvold L \& Johnson JA 2014 Clinical review: effect of vitamin D3 supplementation on improving glucose homeostasis and preventing diabetes: a systematic review and metaanalysis. Journal of Clinical Endocrinology and Metabolism 99 3551-3560. (https://doi.org/10.1210/jc.2014-2136) 
Seuter SA, Neme A, Carlberg C 2016 Epigenome-wide effects of vitamin $\mathrm{D}$ and their impact on the transcriptome of human monocytes involve CTCF. Nucleic Acids Research 44 4090-4104. (https://doi. org/10.1093/nar/gkv1519)

Singh PK, van den Berg PR, Long MD, Vreugdenhil A, Grieshober L, Ochs-Balcom HM, Wang J, Delcambre S, Heikkinen S, Carlberg C, Campbell MJ, Sucheston-Campbell LE 2017 Integration of VDR genome wide binding and GWAS genetic variation data reveals co-occurrence of VDR and NF-кB binding that is linked to immune phenotypes. BMC Genomics 18 132. (https://doi.org/10.1186/s12864017-3481-4)

Smoot ME, Ono K, Ruscheinski J, Wang PL \& Ideker T 2011 Cytoscape 2.8: new features for data integration and network visualization. Bioinformatics 27 431-432. (https://doi.org/10.1093/bioinformatics/ btq675)

Szeles L, Keresztes G, Torocsik D, Balajthy Z, Krenacs L, Poliska S, Steinmeyer A, Zuegel U, Pruenster M, Rot A, et al. 2009 1,25-Dihydroxyvitamin D3 is an autonomous regulator of the transcriptional changes leading to a tolerogenic dendritic cell phenotype. Journal of Immunology 182 2074-2083. (https://doi. org/10.4049/jimmunol.0803345)

van Iersel MP, Kelder T, Pico AR, Hanspers K, Coort S, Conklin BR \& Evelo C 2008 Presenting and exploring biological pathways with PathVisio. BMC Bioinformatics 9 399. (https://doi.org/10.1186/14712105-9-399)

van Iersel MP, Pico AR, Kelder T, Gao J, Ho I, Hanspers K, Conklin BR \& Evelo CT 2010 The BridgeDb framework: standardized access to gene, protein and metabolite identifier mapping services. $B M C$ Bioinformatics 11 5. (https://doi.org/10.1186/1471-2105-11-5)
Vanherwegen AS, Gysemans C \& Mathieu C 2017 Vitamin D endocrinology on the cross-road between immunity and metabolism. Molecular and Cellular Endocrinology 453 52-67. (https:// doi.org/10.1016/j.mce.2017.04.018)

Vats D, Mukundan L, Odegaard JI, Zhang L, Smith KL, Morel CR, Wagner RA, Greaves DR, Murray PJ \& Chawla A 2006 Oxidative metabolism and PGC-1beta attenuate macrophage-mediated inflammation. Cell Metabolism 4 13-24. (https://doi.org/10.1016/j. cmet.2006.05.011)

Verway M, Bouttier M, Wang TT, Carrier M, Calderon M, An BS, Devemy E, McIntosh F, Divangahi M, Behr MA, et al. 2013 Vitamin $\mathrm{D}$ induces interleukin-1beta expression: paracrine macrophage epithelial signaling controls M. tuberculosis infection. PLoS Pathogens 9 e1003407. (https://doi.org/10.1371/journal.ppat.1003407)

Waagmeester A, Hanspers K, Kutmon M, Roudbari Z, Pico A, Kuchinsky A, \& van Iersel M 2017 Oxidative Phosphorylation (Homo sapiens). (available at www.wikipathways.org/instance/WP623_r86899)

Wei R \& Christakos S 2015 Mechanisms underlying the regulation of innate and adaptive immunity by vitamin D. Nutrients 7 8251-8260. (https://doi.org/10.3390/nu7105392)

Wheelwright M, Kim EW, Inkeles MS, De Leon A, Pellegrini M, Krutzik SR \& Liu PT 2014 All-trans retinoic acid-triggered antimicrobial activity against Mycobacterium tuberculosis is dependent on NPC2. Journal of Immunology 192 2280-2290. (https:// doi.org/10.4049/jimmunol.1301686)

Workman C, Jensen LJ, Jarmer H, Berka R, Gautier L, Nielser HB, Saxild HH, Nielsen C, Brunak S \& Knudsen S 2002 A new non-linear normalization method for reducing variability in DNA microarray experiments. Genome Biology 3 research0048.

Received in final form 16 November 2017

Accepted 11 December 2017

Accepted Preprint published online 12 December 2017
(C) 2018 Society for Endocrinology Published by Bioscientifica Ltd. Printed in Great Britain 